\title{
A comparison of Coomassie blue dye with radioiodinated albumin as an indicator for plasma volume estimation in human subjects
}

\author{
IAN S. MENZIES ${ }^{1}$ \\ From the Department of Chemical Pathology, Hospital for Sick Children, \\ Great Ormond Street, London, and the Department of Pathology, \\ St. Helier Hospital, Carshalton, Surrey
}

SYNOPSIS Plasma volume has been estimated in 10 human subjects using Coomassie blue and ${ }^{131}$ I radioiodinated human serum albumin dilution methods simultaneously.

Three different methods of correction used by previous workers to overcome the error due to early dye loss were applied. Satisfactory agreement with the established radioiodinated albumin method was only obtained by extrapolation of the semilogarithmic plot of Coomassie blue plasma dye concentration between five and 10 minutes to the time of injection.

The significance of the controversial Evans blue 'mixing curve' is discussed. An analogous phase in the Coomassie blue disappearance slope is considered to be due to initial rapid loss of dye from the circulation rather than to the process of mixing.

It is shown that Coomassie blue fulfils the criteria listed in the discussion for plasma volume estimation.

The mono-azo dye Coomassie blue was introduced as an indicator label for intravenous use in 1959 (Taylor and Thorp, 1959). Like Evans blue (T 1824) it becomes bound to albumin after injection, and is therefore distributed throughout the albumin space; but it has the advantages of reduced toxicity and more rapid clearance (Taylor and Thorp, 1959; Taylor and Shillingford, 1959).

Despite the introduction of reliable isotopedilution techniques for blood volume estimation, there still appears to be a place for dye dilution methods. The latter are free from irradiation hazards and can be used in departments lacking facilities for the use of radioisotopes. Correction for plasma volume changes may be necessary during intravascular studies with isotopically labelled material. For this purpose plasma volume estimation by a dye dilution technique may be preferable to the use of a second isotope.

Though Coomassie blue has proved satisfactory for cardiac output studies (Taylor and Shillingford, 1959; Bruce and Shillingford, 1962; Payne, 1964),

'Present address: Department of Clinical Chemistry, St. Thomas's Hospital, London S.E.1.

Received for publication 17 September 1965. reports on its value for the estimation of plasma volume have been conflicting (Martin, 1961; Parry and Tuckman, 1961; Martin and Fuller, 1963; Payne, 1964). This arises from the difficulty of finding a satisfactory method of correction for early loss of dye from the circulation.

In the present study plasma volume estimations in a group of human subjects applying different extrapolations to the Coomassie blue disappearance slope are compared with simultaneous estimations using the ${ }^{131}$ I human serum albumin method. The purpose of this was to discover which, if any, type of extrapolation correction could be found to give reliable agreement with the established isotope method.

\section{MATERIALS}

COOMASSIE BLUE Coomassie blue $2 \%$ aqueous solution for intravenous injection (obtained from Imperial Chemical Industries Ltd. in $5 \mathrm{ml}$. ampoules). The amount used for a single injection in adults was $6 \mathrm{ml}$. irrespective of body weight.

${ }^{131}$ I HUMAN SERUM ALBUMIN This was obtained from the Radiochemical Centre, Amersham, Bucks. Less than 3\% 
of unbound radioactivity was contained in the material used (Bayly, 1964).

Adults were given approximately 4 microcuries in $10 \mathrm{ml}$. of physiological saline with $100 \mathrm{mg}$. additional human albumin to minimize loss of label onto glass.

MIXED DYE-ISOTOPE SOLUTION FOR INJECTION Of the $2 \%$ Coomassie blue $8 \mathrm{ml}$. was mixed with $7 \mathrm{ml}$. of physiological saline containing 4 microcuries of ${ }^{131} \mathrm{I}$ human serum albumin and $120 \mathrm{mg}$. of additional albumin. Subjects marked with ${ }^{1}$ in Table I were given $10 \mathrm{ml}$. of this solution instead of consecutive dye and ${ }^{131}$ I human serum albumin.

${ }^{51} \mathrm{Cr}$ SODIUM CHROMATE This label, obtained from the Radiochemical Centre, was used to label autologous erythrocytes. Venous blood, $10 \mathrm{ml}$., was taken from the prospective subject into acid citrate dextrose ${ }^{2}$ solution and the plasma discarded after centrifugation. The cells were incubated at $37^{\circ} \mathrm{C}$. for 15 minutes with approximately 30 microcuries of ${ }^{51} \mathrm{Cr}$ sodium chromate, and then washed three times with sterile physiological saline. All centrifugations were performed at 1,000 r.p.m. or less to avoid damage to erythrocytes.

Of the final suspension in physiological saline, $10 \mathrm{ml}$. was injected into the subject within one hour.

\section{METHODS}

After the subject had been recumbent for 30 minutes $10 \mathrm{ml}$. of blood (for plasma blanks and haematology) was withdrawn from an arm vein, and, using the same intravenous needle, the prepared label solution was immediately injected over a period of 20 to 40 seconds. Injection syringes were kept for calibration, and aliquots of the label solutions were preserved for making standards.

At five and $10 \mathrm{~min}$. after the injection, $5 \mathrm{ml}$. samples of blood were obtained by separate venepuncture from the opposite arm. Further samples were taken at intervals between 10 and 30 minutes and in some instances within the first five-minute period.

The beginning and end of each procedure was carefully recorded with a stop-watch so that mean injection and sampling times could be calculated. A tourniquet was used during the venepunctures, but this was strictly limited to a period of a few seconds so that venous stasis was minimal.

Blood samples were taken into tubes containing dry heparin, the plasma separated without delay and kept at $4^{\circ} \mathrm{C}$. until dye concentration and ${ }^{131} \mathrm{I}$ H.S.A. radiation levels could be estimated. Dye estimations were performed within a week, and radiation counting within $\mathbf{4 8}$ hours of obtaining the samples.

Injection syringes were calibrated by weighing (in duplicate) the amount of distilled water discharged after filling to the relevant mark. This weight, in grams, was taken as a measure of the volume in millilitres of dye or other label solution injected.

estimation of Plasma dye level Plasma dye levels were estimated by the urea-acetone dye extraction method of Clausen and Lifson (1956), a detailed account of 'Disodium citrate, 2 g., and glucose (dextrose) 3 g., in $120 \mathrm{ml}$. pyrogenfree distilled water. which is supplied by I.C.I. with their dye product. Standard solutions for photometric comparison were made from the dye solution used for injection.

Extracts of plasma blank, dyed plasma samples, and standard were read against an acetone (A.R.) reference on an EEL long-cell absorptiometer using an Ilford 606 응 $(580 \mathrm{~m} \mu)$ filter.

Plasma dye levels were calculated using the following formula:-

Plasma dye level (in mg. per $100 \mathrm{ml}$.) $=\frac{\text { P-B }}{\text { std. }} \times 5$

Where $\mathbf{P}$ is the dyed plasma sample reading, $\mathbf{B}$ is the plasma blank reading, and std. is the $5 \mathrm{mg}$. per $100 \mathrm{ml} . \widehat{\circ}$ standard reading. A $5 \mathrm{mg}$. per $100 \mathrm{ml}$. standard is satisfactory for the plasma dye levels obtained.

CALCULATION OF PLASMA VOLUME FROM PLASMA DYE LEVELS Correction for dye loss was made by variouso extrapolations (described later) of a semilogarithmic plot of plasma dye levels against time, similar in construc $-\overrightarrow{-}$ tion to that shown in Figure 1. Timing was calculateक from halfway through the period of label injection ('zero time') to halfway through the duration of each' respective venepuncture.

The corrected plasma dye level was used in the follow ing formula:-

Plasma volume (in ml.) $=\frac{\text { Amount of dye injected (in mg.) }}{\text { Corrected plasma dye level (in mg. per ml. }}$

The amount of dye injected in milligrams was calcu lated by multiplying the syringe calibration volume in millilitres by the concentration of dye in the injection $\vec{B}$ solution expressed as milligrams per millilitre.

ESTIMATION OF ${ }^{131}$ I HUMAN SERUM ALBUMIN AND ${ }^{51} \mathrm{Cr}$ LABELLED ERYTHROCYTE RADIOACTIVITY LEVELS ThS radioactivity of 2 or $4 \mathrm{ml}$. volumes of plasma or whole blood (for ${ }^{131}$ I human serum albumin or ${ }^{51} \mathrm{Cr}$-labelleक्? erythrocytes respectively) and of the corresponding standard solutions was estimated using a well-type scintillation counter.

CALCULATION OF PLASMA VOLUME FROM PLASMA RADIOACTIVITY LEVELS The formula used was as follows을 Plasma volume (in ml.) $=$ Radioactivity of injected solution per m Plasma volume $($ in $\mathrm{ml})=.\frac{\times \text { volume injected }(\mathrm{ml} .)}{\text { Radioactivity of plasma per } \mathrm{ml} .}$

The plasma radioactivity used in this formula was corrected for the rate of disappearance of injectee albumin by extrapolation of a 10 to 25 minute semi? logarithmic plot, or by multiplying the 10-minut radioactivity level by 1.015 in cases when samples were not obtained after the first 10 minutes (Hart and Metzo 1962).

DEFINITION OF TERMS USED TO DESCRIBE PARTS OF THID PLASMA DYE CURVE After intravenous injection of Coomassie blue the plasma dye level usually rises rapidly 
for between one and two and a half minutes to reach a maximum. Afterwards there is a progressive fall, a semilogarithmic plot of which (Fig. 1) shows the presence of two exponential phases; the first, usually lasting between 10 and 15 minutes from the time of dye injection, being of steeper gradient than the second (Parry and Tuckman, 1961; Martin, 1961). In the present discussion these are called phases I and II of the dye disappearance slope.

\section{RESULTS}

PLASMA VOLUME ESTIMATES PERFORMED SIMULTANEOUSLY BY 131 I HUMAN SERUM ALBUMIN AND COOMASSIE BLUE METHODS Coomassie blue and ${ }^{131}$ I human serum albumin were injected simultaneously on 12 occasions involving 10 different subjects. The clinical diagnoses and other data are listed on Table I.

Plasma dye concentrations were corrected by extrapolation of a semilogarithmic plot of dye level against time (Fig. 1) using phase I to zero time and to 3.5 minutes in all 12 instances, and phase II to zero time in eight.

Since the collection of more blood samples was often impracticable it was decided to base phase I extrapolation on dye levels as near as possible to five and 10 minutes after dye injection. These times fall within the duration of phase $I$ in the majority of instances while being well enough spaced to minimize the effect of errors in plasma dye estimation on the

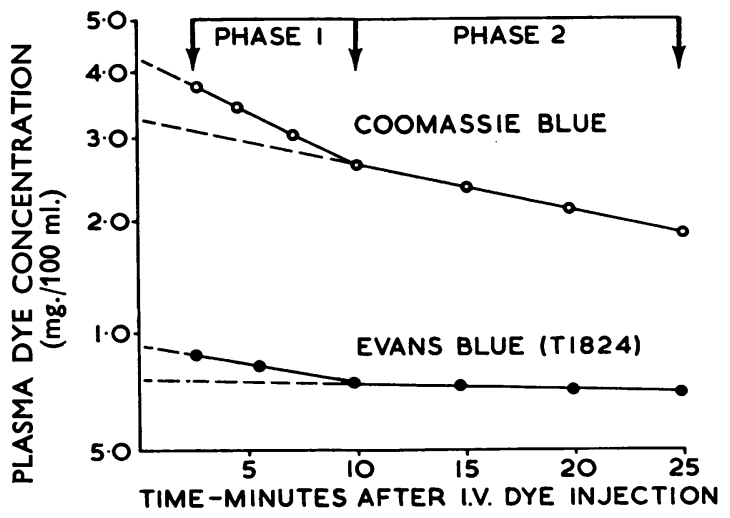

FIG. 1. Dye disappearance slopes of Coomassie blue and Evans blue ( $T$ 1824). These are typical semilogarithmic plots of plasma dye level in $\mathrm{mg}$. per $100 \mathrm{ml}$. against time in minutes after intravenous injection of the quantities usually employed for adults.

slope. Phase II extrapolation was based on the line giving the best 'fit' to dye levels obtained between 10 and 30 minutes.

Close agreement was consistently obtained only when correction by extrapolation of phase I to zero time was applied to the dye method.

CORRECTION OF PLASMA DYE LEVELS BY THE EXTRATION FACTOR The extraction factor correction

\section{TABLE I}

RESULTS OF PLASMA VOLUME ESTIMATION USING ${ }^{131}$ I HUMAN SERUM ALBUMIN AND COOMASSIE BLUE DILUTION METHODS

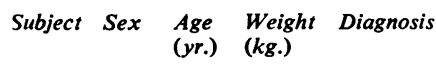

Plasma Volume Estimates ( $\mathrm{ml}$.)

\begin{tabular}{|c|c|c|c|c|c|c|c|c|c|c|c|c|c|}
\hline \multirow[t]{2}{*}{ Subject } & \multirow[t]{2}{*}{$\operatorname{Sex}$} & \multirow[t]{2}{*}{$\begin{array}{l}\text { Age } \\
(y r .)\end{array}$} & \multirow[t]{2}{*}{$\begin{array}{l}\text { Weight } \\
(\text { kg.) }\end{array}$} & \multirow[t]{2}{*}{ Diagnosis } & \multirow[t]{2}{*}{$\begin{array}{l}\text { Haemo- } \\
\text { globin } \\
(\mathrm{g} . / \\
100 \mathrm{ml} .)\end{array}$} & \multirow[t]{2}{*}{$\begin{array}{l}\text { Venous } \\
P . C . V . \\
(\%)\end{array}$} & \multirow[t]{2}{*}{$\begin{array}{l}{ }^{131} I \\
\text { H.S.A. } \\
\text { Method }\end{array}$} & \multicolumn{3}{|c|}{$\begin{array}{l}\text { Coomassie Blue Method } \\
\text { Using Different Extra- } \\
\text { polations }\end{array}$} & \multicolumn{3}{|c|}{$\begin{array}{l}\text { Percentage Difference } \\
\text { between } 131 \text { I Human Serum } \\
\text { Albumin Methods Using } \\
\text { Different Extrapolations }\end{array}$} \\
\hline & & & & & & & & $\begin{array}{l}\text { Phase I } \\
\text { to Zero } \\
\text { Time }\end{array}$ & $\begin{array}{l}\text { Phase I } \\
\text { to } 3 \cdot 5 \\
\text { Minutes }\end{array}$ & $\begin{array}{l}\text { Phase II } \\
\text { to Zero } \\
\text { Time }\end{array}$ & $\begin{array}{l}\text { Phase I } \\
\text { Zero } \\
\text { Time }\end{array}$ & $\begin{array}{l}\text { Phase I to } \\
3 \cdot 5 \\
\text { Minutes }\end{array}$ & $\begin{array}{l}\text { Phase II } \\
\text { Time } \\
\text { Zero }\end{array}$ \\
\hline S.H. & $\mathbf{M}$ & 5 & $12 \cdot 5$ & Fibrocystic disease of pancreas & & 37 & 700 & 717 & 920 & & $\begin{array}{l}+2 \cdot 4 \\
+2.4\end{array}$ & $\begin{array}{l}+27 \cdot 0 \\
+12 \cdot 2\end{array}$ & \\
\hline $\begin{array}{l}\text { I.S.M. } \\
\text { I.S.M. }\end{array}$ & $\mathbf{M}$ & $\begin{array}{l}35 \\
35\end{array}$ & $\begin{array}{l}89 \\
89\end{array}$ & $\begin{array}{l}\text { Healthy } 2.4 .64 \\
\text { Healthy } 28.4 .64\end{array}$ & $\begin{array}{l}14 \cdot 0 \\
14 \cdot 0\end{array}$ & $\begin{array}{l}45 \\
45\end{array}$ & $\begin{array}{l}3,310 \\
3,450\end{array}$ & $\begin{array}{l}3,390 \\
3,430\end{array}$ & $\begin{array}{l}3,740 \\
3,680\end{array}$ & $\begin{array}{l}3,740 \\
3,680\end{array}$ & $\begin{array}{l}+2.4 \\
-0.6\end{array}$ & $\begin{array}{l}+12 \cdot 2 \\
+6 \cdot 4\end{array}$ & $\begin{array}{l}+12 \cdot 2 \\
+6 \cdot 4\end{array}$ \\
\hline $\begin{array}{l}\text { I.S.M. } \\
\text { A.E. }\end{array}$ & $\mathbf{M}$ & 46 & 75 & $\begin{array}{l}\text { Macroglobulinaemia with cold } \\
\text { haemoglobinuria }\end{array}$ & $5 \cdot 7$ & 30 & 6,700 & 6,800 & 7,830 & 7,420 & $+1 \cdot 5$ & $+15 \cdot 6$ & $+10 \cdot 3$ \\
\hline F.L. & $\mathbf{M}$ & 63 & 50 & $\begin{array}{l}\text { Iron-deficiency anaemia, responding } \\
\text { (12.5.64) }\end{array}$ & $10 \cdot 3$ & $32 \cdot 5$ & 3,000 & 3,170 & 3,390 & 3,250 & $+5 \cdot 5$ & $+10 \cdot 6$ & $+8 \cdot 0$ \\
\hline G.B. & $\mathbf{M}$ & 68 & - & $\begin{array}{l}\text { Chronic bronchitis with mild } \\
\text { congestive cardiac failure }\end{array}$ & $11 \cdot 3$ & 37 & 2,820 & 2,800 & 3,100 & 3,030 & -0.7 & $+9 \cdot 4$ & $+7 \cdot 2$ \\
\hline B.M. & $\mathbf{M}$ & 72 & - & $\begin{array}{l}\text { Chronic bronchitis with severe } \\
\text { congestive cardiac failure }\end{array}$ & $14 \cdot 1$ & 52 & 3,000 & 3,010 & 3,250 & 3,130 & +0.3 & +8.0 & $+4 \cdot 3$ \\
\hline G.R. & $\mathbf{F}$ & 72 & 43 & $\begin{array}{l}\text { Pernicious anaemia, responding } \\
(23.8 .64)\end{array}$ & $8 \cdot 7$ & 8 & 2,130 & 2,160 & 2,440 & - & $+1 \cdot 4$ & +13.6 & - \\
\hline G.R. & $\mathbf{F}$ & 72 & 43 & $\begin{array}{l}\text { Pernicious anaemia, responding } \\
\text { (26.8.64) }\end{array}$ & $8 \cdot 55$ & $27 \cdot 5$ & 2,310 & 2,350 & 2,570 & - & $+1 \cdot 7$ & +10.7 & - \\
\hline E.E. & $\mathbf{F}$ & 80 & - & $\begin{array}{l}\text { Pernicious anaemia with iron } \\
\text { deficiency }\end{array}$ & $5 \cdot 4$ & 25 & 2,950 & 2,970 & 3,310 & 3,140 & +0.7 & $+11 \cdot 5$ & $+6 \cdot 2$ \\
\hline $\begin{array}{l}\text { A.W. } \\
\text { L.C. }\end{array}$ & $\begin{array}{l}\mathbf{F} \\
\mathbf{F}\end{array}$ & $\begin{array}{l}82 \\
86\end{array}$ & - & $\begin{array}{l}\text { Pernicious anaemia } \\
\text { Iron-deficiency anaemia }\end{array}$ & $\begin{array}{l}3 \cdot 5 \\
5 \cdot 1\end{array}$ & $\begin{array}{l}10 \\
21 \cdot 5\end{array}$ & $\begin{array}{l}2,600 \\
2,370\end{array}$ & $\begin{array}{l}2,610 \\
2,420\end{array}$ & $\begin{array}{l}2,680 \\
2,620\end{array}$ & $\overline{2,590}$ & $\begin{array}{l}+0.4 \\
+2.1\end{array}$ & $\begin{array}{l}+3.0 \\
+10.0\end{array}$ & +8.9 \\
\hline
\end{tabular}

I.S.A. and Coomassie blue were mixed before injection in these instances. 
described by Clausen and Lifson (1956) was found to make the difference between dye and ${ }^{131}$ I human serum albumin plasma volume estimates greater in nine and less (by $0.6 \%$ ) in only one of the 12 studies described. The mean of 53 extraction factor determinations in 19 different subjects was $100.1 \%$. The error involved in the measurement of the extraction factor appeared to be greater than the error it was intended to remove, therefore it has not been applied.

CORRELATION BETWEEN MIXING TIME, ESTIMATED BY ISOTOPE METHODS, AND THE DURATION OF PHASE I OF THE DYE DISAPPEARANCE SLOPE Phase I was measured to the point of interception between the phase I and II portions of the semilogarithmic dye disappearance slope (Fig. 1), while mixing was considered complete when radioactivity levels had become stabilized within the limits of accuracy for the procedure involved (Strumia, Colwell, and Dugan, 1958).

In 15 studies performed mixing was complete by five minutes or earlier, whereas phase I of the dye disappearance slope was more than 10 minutes in all but three.

A.E., a subject with macroglobulinaemia, deserves special mention. Despite a considerable increase in blood viscosity appreciable at $37^{\circ} \mathrm{C}$., due to a very high plasma protein level $(12.0 \mathrm{~g}$. per $100 \mathrm{ml}$., mostly macroglobulin), and also a correspondingly increased circulating plasma volume, mixing was complete within a period of five minutes after injection of ${ }^{131}$ I human serum albumin.

A DOUBLE INJECTION EXPERIMENT WITH COOMASSIE BLUE Figure 2 shows a semilogarithmic plot of plasma dye levels against time after two consecutive intravenous injections of similar amounts of Coo-

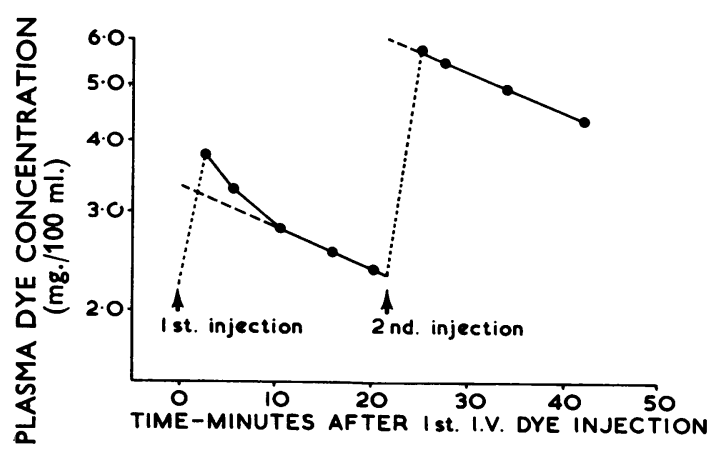

FIG. 2. Dye disappearance slopes following two consecutive injections of Coomassie blue presented as a semilogarithmic plot of plasma dye concentration in $\mathrm{mg}$. per $100 \mathrm{ml}$. against time in minutes in subject F.L. massie blue. The second injection was of simili duration to the first, and was administered 21.5 minutes later at a time when the plasma dye level was still raised.

The slopes of phases I and II were quite distine following the first injection and identical followifig the second.

\section{DISCUSSION}

Estimation of the plasma volume has always involved some form of label dilution technique, the suitabiliny of a label for the purpose depending upon the folloging criteria: freedom from harmful side effects when administered intravenously in amounts producing suitably high plasma concentration; accurate determination of plasma concentration of the label shoukd be possible; it should remain in the plasma aftr intravenous injection, either without loss, or with-a loss that can be measured and corrected for un 71 mixing is complete. However, elimination of the label between consecutive estimations by reducifing toxicity and inaccuracy caused by accumulation $\overrightarrow{\vec{\omega}}$ advantageous.

Evans blue ( $T$ 1824), widely used for plasiog volume estimation, has characteristics which afe similar to Coomassie blue, including the biphasic form of the dye disappearance slope shown in Figol 1 (Parry and Tuckman, 1961). Gibson and Evams (1937) used an extrapolation of the second of these two phases to zero time in order to correct for eaब dye loss. They avoided the first phase (seven to 12 minutes in duration) considering it to be a 'mixi鸾g curve'.

This method has since been questioned on grounds that the first phase of the dye disappearanice slope really represented an initial rapid loss of dye rather than mixing. The following are observations upon which this criticism has been based: some batches of T 1824 were found to contain coloured impurities that would escape rapidly from the circulation (Gregersen and Gibson, 1937; Crooke and Morris, 1942); abolition of the so-called 'mixing curve' produced by a preliminary saturating dose.8f dye or indian ink (Cruickshank and Whitfießs, 1945); modification of the 'mixing curve' productesd when protein-bound as opposed to free dye was administered (Meneely, Wells, and Hahn, 194§; evidence that mixing was complete before the 'mixing curve' had terminated (Cruickshank afipd Whitfield, 1945; Strumia et al., 1958).

An indispensable method for establishing the value of a label for plasma volume estimation दु $_{s}$ comparison with an established method, both beigg used simultaneously in the same subject. Gogd agreement between different methods, though 
failing to define the exact anatomical boundaries of the space in question, at least lend it a practical significance and gives confidence in its measurement.

Studies in human subjects have been performed comparing T 1824 with labelled erythrocyte methods (Meneely et al., 1947; Barnes, Loutit, and Reeve, 1948; Strumia et al., 1958) or with radioiodinated albumin (Schultz, Hammarsten, Heller, and Ebert, 1953), but conclusions regarding the occurrence of an early substantial dye loss are at variance. The magnitude of the errors involved in these procedures (Senn and Karlson, 1958) may partly explain this lack of agreement. In particular, though dye extraction techniques have been available (Crooke and Morris, 1942; Chinard and Eder, 1948; Allen, 1953), most published work has involved the original non-extraction method for measuring dye level (Gibson and Evelyn, 1938), which is subject to greater inaccuracy. The low T 1824 dosage necessary to avoid prolonged skin discoloration is an additional source of error.

Furthermore, where an erythrocyte label is used for comparison with $\mathrm{T} 1824$, discrepancy between venous and whole-body haematocrit becomes an additional embarrassment. Comparisons made between labels that initially occupy the same part of the intravascular space, as do radioiodinated albumin and $\mathrm{T} 1824$, are more satisfactory in this respect.

Unlike T 1824, Coomassie blue is excreted actively by the liver so that, unless there is hepatic insufficiency (Martin and Fuller, 1963), phase II of the disappearance slope presents quite a steep gradient (Fig. 1). Larger quantities of Coomassie blue can therefore be administered without fear of prolonged skin discoloration, which increases the accuracy of plasma volume estimation.

Several attempts have been made to determine the value of Coomassie blue for plasma volume estimation. Parry and Tuckman (1961) made a comparative study of this dye and ${ }^{131}$ I human serum albumin applying the original 'post mixing' (phase II to zero time) extrapolation correction of Gibson and Evans (1937), and found Coomassie blue to give values that were inconsistently high, suggesting a substantial early dye loss. The results of the present study are in agreement with this.

Martin and Fuller (1963) considered the dye to be fully mixed 3.5 minutes after injection, at which time the dye level gave plasma volume estimates comparing well with those anticipated on the basis of body weight and height. Since the phase I semilogarithmic dye slope is known to give a straight line plot over the period in question, extrapolation to 3.5 minutes should provide the dye level referred to by these authors. In the present study results calculated on this basis gave less satisfactory results than those obtained using the traditional phase II to zero time extrapolation.

Payne (1964) found that phase I extrapolation to zero time based on samples taken at three and 10 minutes after the injection of Coomassie blue gave plasma volume estimate falling within the accepted normal range based on body weight. Results in the present study based on samples taken at five and 10 minutes give a close agreement with the ${ }^{131}$ I human serum albumin estimates and therefore support the validity of this extrapolation.

Even in normal subjects plasma volumes estimated from body weight, height, or surface area have too wide a margin of variation to be suitable as a criterion of the validity of dilution techniques and this may explain the lack of agreement between the present conclusions and those of Martin and Fuller (1963).

Theoretically, extrapolation of phase I of the dye disappearance slope as a valid correction for initial dye loss requires that it should not represent mixing to any significant extent. Since mixing of isotopelabelled erythrocytes and albumin was found to be complete in all the cases studied within five minutes of injection (Table II), the five to 10 minute portion of the dye slope fulfils this requirement. Furthermore abolition of the steeper, phase I portion, of the dye slope following the second of two consecutive dye injections (Fig. 2) suggests that the increased gradient of phase $I$ is due to dye absorption onto tissue

\section{TABLE II}

RELATIONSHIP BETWEEN MIXING TIME ESTIMATED BY RADIOISOTOPIC METHODS AND THE DURATION OF PHASE I OF THE COOMASSIE BLUE DISAPPEARANCE SLOPE DETERMINED SIMULTANEOUSLY ${ }^{1}$

\begin{tabular}{|c|c|c|c|}
\hline \multirow[t]{2}{*}{ Subject } & \multicolumn{2}{|c|}{$\begin{array}{l}\text { Time for Completion of Mixing } \\
\text { (min.) }\end{array}$} & \multirow{2}{*}{$\begin{array}{l}\text { Duration of } \\
\text { Phase I of } \\
\text { Coomassie Blue } \\
\text { Dye Disappear- } \\
\text { ance Slope (min.) }\end{array}$} \\
\hline & $\begin{array}{l}{ }^{11} \text { Cr-labelled } \\
\text { Erythrocyte } \\
\text { Method }\end{array}$ & $\begin{array}{l}{ }^{131} \text { I Human } \\
\text { Serum Albumin } \\
\text { Method }\end{array}$ & \\
\hline
\end{tabular}

\begin{tabular}{|c|c|c|c|}
\hline I.S.M. & $3 \cdot 5^{2}$ & $5 \cdot 5^{2}$ & $12 \cdot 0$ \\
\hline I.S.M. & - & $4 \cdot 5^{2}$ & 15.0 \\
\hline A.E. & - & $5 \cdot 0^{2}$ & 11.0 \\
\hline F.L. & 2.0 to 4.0 & - & 10.5 \\
\hline F.L. & 2.0 to 4.5 & $2 \cdot 5^{2}$ & $11 \cdot 5$ \\
\hline F.L. & - & $4 \cdot 5^{2}$ & $12 \cdot 5$ \\
\hline G.B. & - & $4 \cdot 5^{2}$ & 9.0 \\
\hline B.M. & - & $4 \cdot 5^{2}$ & $12 \cdot 5$ \\
\hline E.E. & - & $5 \cdot 0^{2}$ & $12 \cdot 5$ \\
\hline L.C. & - & $4 \cdot 5^{2}$ & 10.0 \\
\hline W.T. & $3 \cdot 5^{2}$ & - & $12 \cdot 5$ \\
\hline W.T. & $3 \cdot 0^{2}$ & $3 \cdot 5^{2}$ & $9 \cdot 0$ \\
\hline W.T. & - & $2 \cdot 0^{2}$ & $7 \cdot 5$ \\
\hline W.T. & - & $3 \cdot 0^{2}$ & 15.0 \\
\hline F.K. & $2 \cdot 5^{2}$ & - & 14 . \\
\hline
\end{tabular}

'Allowance has been made for delay between consecutive injections of label.

'In these instances mixing had already become complete before the first blood sample was taken at the time recorded. 
structures that soon become saturated, or possibly reabsorption from the gut.

I am grateful to Dr. B. E. Clayton and Dr. L. Bernstock for their encouragement and help with the preparation of this paper; to Dr. Cedric Hirson for organizing many of the subjects; to the physicians of St. Helier Hospital for permission to investigate their patients, and to Dr. A. P. Norman for permission to study the subject $\mathbf{S}$. $\mathbf{H}$.

I also wish to thank Dr. R. Sephton Smith and Mrs. Mary Heeley, lately of the Department of Haematological Research at the Hospital for Sick Children, Great Ormond Street, for valuable assistance with the radioisotopic techniques involved.

\section{REFERENCES}

Allen, T. H. (1953). Amer. J. Physiol., 175, 227.

Barnes, D. W. H., Loutit, J. F., and Reeve. E. B. (1948). Clin. Sci., 7, 155.
Bayly, R. J. (1964). Personal communication.

Bruce, T. A., and Shillingford, J. P. (1962). Brit. Heart J., 24, 69.

Chinard, F. P., and Eder, H. A. (1948). J. exp. Med., 87, 473.

Clausen, D. F., and Lifson, N. (1956). Proc. Soc. exp. Biol. (N. Y.), ब्व], 11.

Crooke, A. C., and Morris, C. J. O. (1942). J. Physiol. (Lond.), 101, $2 \pm 7$

Cruickshank, E. W. H., and Whitfield, I. C. (1945). Ibid., 104, 52.

Gibson, J. G., II, and Evans, W. A., Jr. (1937). Ibid., 16, 301.

and Evelyn, K. A. (1938). Ibid., 17, 153

Gregersen, M. I., and Gibson, J. G., II. (1937). Amer. J. Physiol., 1 494.

Hart, D., and Metz, J. (1962). J. clin. Path., 15, 459.

Martin, W. B. (1961). Amer. J. med. Sci., 242, 342.

— and Fuller, J. (1963). Ibid., 245, 556

Meneely, G. R., Wells, E. B., and Hahn, P. F. (1947). Amer $\rightarrow$ Physiol., 148, 531.

Parry, E. H. O., and Tuckman, J. (1961), Brit. Heart J., 23, 150.

Payne, J. P. (1964). Ann. roy. Coll. Surg. Engl., 34, 384.

Schultz, A. L., Hammarsten, J. F., Heller, B. I., and Ebert, R. $\frac{\Omega}{\square}$ (1953). J. clin. Invest., 32, 107.

Senn, L. Y., and Karlson, K. E. (1958). Surgery, 44, 1095.

Strumia, M. M., Colwell, L. S., and Dugan, A. (1958). Blood, 13, A28.

Taylor, S. H., and Shillingford, J. P. (1959). Brit. Heart J., 21, 49

— and Thorp, J. M. (1959). Ibid., 21, 492. 